\title{
Genetic and metabolic predictors of chemosensitivity in oligodendroglial neoplasms
}

\author{
C Walker*, , B Haylock², D Husband ${ }^{2}$, KA Joyce', D Fildes', MD Jenkinson ${ }^{3,4}$, T Smith ${ }^{3}$, J Broome ${ }^{3}$, K Kopitzki $^{4}$, \\ DG du Plessis ${ }^{4}$, J Prosser ${ }^{5}$, S Vinjamuri ${ }^{5}$ and PC Warnke ${ }^{4}$ \\ 'JK Douglas Laboratories, Clatterbridge Hospital, Bebington, Wirral CH63 4JY, UK; ${ }^{2}$ Clatterbridge Centre for Oncology, Bebington, Wirral CH63 4JY, UK; \\ ${ }^{3}$ Walton Centre for Neurology and Neurosurgery, Liverpool L9 7LJ, UK; ${ }^{4}$ Division of Neuroscience, University of Liverpool, Liverpool L9 7LJ, UK; \\ ${ }^{5}$ Department of Nuclear Medicine, Royal Liverpool University Hospital, Liverpool L7 8XP, UK
}

The $-1 p /-19 q$ genotype predicts chemosensitivity in oligodendroglial neoplasms, but some with intact $1 p / 19 q$ also respond and not all with $I \mathrm{p} / \mathrm{I} 9 \mathrm{q}$ loss derive durable benefit from chemotherapy. We have evaluated the predictive and prognostic significance of pretherapy ${ }^{201} \mathrm{TI}$ and ${ }^{18} \mathrm{~F}$-FDG SPECT and genotype in 38 primary and 10 recurrent oligodendroglial neoplasms following PCV chemotherapy. I / /9q loss was seen in 8/I5 OII, 6/15 OAll, 7/7 OIII, 3/II OAlll and was associated with response (FisherExact: $P=0.000$ ) and prolonged progression-free (log-rank: $P=0.002$ ) and overall survival $(O S)$ (log-rank: $P=0.0048$ ). Response was unrelated to metabolism, with tumours with high or low metabolism showing response. Increased ${ }^{18} \mathrm{~F}$-FDG or ${ }^{201} \mathrm{TI}$ uptake predicted shorter progression-free survival (PFS) in the series (log-rank: ${ }^{201} \mathrm{TI} P=0.0097$, ${ }^{18} \mathrm{~F}$-FDG $P=0.0170$ ) and in cases with or without the $-1 \mathrm{p} /-19 \mathrm{q}$ genotype. Elevated metabolism was associated with shorter OS in cases with intact $1 \mathrm{p} / 19 \mathrm{q}\left(\log\right.$-rank: ${ }^{18} \mathrm{~F}$ FDG $P=0.0077 ;{ }^{201} \mathrm{Tl} P=0.0004$ ) and shorter PFS in responders (log-rank: ${ }^{18} \mathrm{~F}-\mathrm{FDG} P=0.005 ;{ }^{201} \mathrm{Tl} P=0.0132$ ). ${ }^{201} \mathrm{Tl}$ uptake and $\mathrm{Ip} / 19 \mathrm{q}$ loss were independent predictors of survival in multivariate analysis. In this initial study, ${ }^{201} \mathrm{Tl}$ and ${ }^{18} \mathrm{~F}$-FDG uptake did not predict response to PCV, but may be associated with poor survival following therapy irrespective of genotype. This may be clinically useful warranting further study.

British Journal of Cancer (2006) 95, |424- |431. doi:1 0.1038/sj.bjc.6603390 www.bjcancer.com

Published online 10 October 2006

(c) 2006 Cancer Research UK

Keywords: oligodendroglioma; ${ }^{201}$ Thallium SPECT; ${ }^{18}$ Fluorodeoxyglucose SPECT; I / /9q loss; chemosensitivity

Oligodendroglial neoplasms with the $-1 \mathrm{p} /-19 \mathrm{q}$ genotype have a more indolent clinical evolution, are associated with prolonged survival and are more likely to be chemosensitive than their morphologically equivalent counterparts with intact $1 \mathrm{p} / 19 \mathrm{q}$ (Cairncross et al, 1998; Smith et al, 2000; van den Bent, 2004). The biological basis behind these clinical differences are not yet well understood, but are likely to result from complex interactions between tumour genetics and host environment, as well as physiological factors that determine drug delivery (Warnke et al, 2003, 2005; Hartmann et al, 2004; Jeuken et al, 2004). Genotype and factors such as blood flow or blood volume and metabolism have been associated with chemoresponsiveness in anaplastic oligodendrogliomas (Warnke, 1998; Engelhard et al, 2003; Jager et al, 2005). Despite responsiveness to therapy, oligodendroglial neoplasms with the $-1 \mathrm{p} /-19 \mathrm{q}$ genotype inevitably recur, sometimes with only short progression-free survival (PFS). Prognostic or predictive factors that may be used to identify patients likely to derive durable clinical benefit are therefore essential.

Metabolic imaging using radiolabeled tracers such as ${ }^{201}$ Thallium or ${ }^{18} \mathrm{~F}$-fluorodeoxyglucose has been used in a number

*Correspondence: Dr C Walker; E-mail: carol.walker@ccrt.nhs.uk

This research was supported by Clatterbridge Cancer Research Trust and the Walton Neurosciences Fund.

Received I0 February 2006; revised I 4 August 2006; accepted 23 August 2006; published online 10 October 2006 of glioma studies, to yield diagnostic or prognostic information (Benard et al, 2003; Padma et al, 2003; Datta et al, 2004), to guide biopsy (Levivier et al, 2002), to distinguish recurrent tumour from radiation necrosis (Stokkel et al, 1999) or monitor response to therapy (Vos et al, 2003) but the relationship between metabolism and chemosensitivity in oligodendroglial neoplasms has still to be determined.

In a multidisciplinary study of oligodendroglial neoplasms undergoing therapy at a single UK treatment centre between 2000 and 2003 , the $-1 \mathrm{p} /-19 \mathrm{q}$ genotype was associated with a more indolent clinical history with longer time to first oncology therapy and prolonged survival from first referral, than cases with intact $1 \mathrm{p} / 19 \mathrm{q}$ (Walker et al, 2005). Response and favourable outcome following procarbazine, lomustine and vincristine (PCV) chemotherapy was strongly associated with the $-1 \mathrm{p} /-19 \mathrm{q}$ genotype (Walker et al, 2006). No relationship was observed between pretherapy single-voxel Magnetic Resonance Spectroscopy and genotype (Jenkinson et al, 2005). In contrast, pretherapy brain Single-Photon Emission Computed Tomography (SPECT) data revealed that tumours with $1 \mathrm{p} / 19 \mathrm{q}$ loss were more likely to show increased ${ }^{201}$ thallium uptake and to a lesser degree, ${ }^{18} \mathrm{~F}$-fluorodeoxyglucose uptake than those without these losses (Walker et al, 2004).

The aim of the present study was to determine whether pre-therapy ${ }^{201} \mathrm{Tl}$ or ${ }^{18} \mathrm{~F}$-FDG SPECT may be used to predict therapeutic response and outcome in oligodendroglial neoplasms treated with PCV chemotherapy and to compare this with genotype. 


\section{PATIENTS AND METHODS}

\section{Case selection and pathology}

Cases for investigation were from a prospective study of adult oligodendroglial tumours at the Walton Centre for Neurology and Neurosurgery/Clatterbridge Center for Oncology diagnosed between May 2000 and July 2003 (Walker et al, 2005). For inclusion in this study, patients had pathology diagnosis and SPECT data pretherapy, were treated by PCV chemotherapy and gave research consent. Cases in this study were included in larger series reporting pretherapy associations between SPECT data, genotype and histopathology $(n=59)$ (Walker et al, 2004) and between genotype and response to PCV chemotherapy $(n=76)$ (Walker et al, 2006). The study had local ethics committee approval. Consensus pathological diagnosis and grading according to current WHO criteria (Kleihues and Cavanee, 2000) was undertaken by two consultant neuropathologists. The study included 38 previously untreated patients (11 oligodendroglioma WHO grade II (OII), 14 oligoastrocytoma WHO grade II (OAII), five oligodendroglioma WHO grade III (OIII), eight oligoastrocytoma WHO grade III (OAIII)) and 10 with tumours that recurred following previous radiotherapy (four OII, one OAII, two OIII, three OAIII). The median time between previous radiotherapy and metabolic imaging was 5.7 years (range $1.1-13.9$ years). The median age was 43 (range 27-71). All patients had surgery prior to therapy. In all, $94 \%$ had biopsy only (three image-guided, 42 serial-stereotactic). Three patients had a partial resection with residual tumour clearly assessable on MRI postsurgery and before nuclear medicine imaging.

\section{${ }^{201}$ Tl SPECT and ${ }^{18}$ F-FDG imaging}

Nuclear medicine imaging was post surgery and pretherapy for 47 patients. One patient had imaging before biopsy and therapy. The median time from surgery to imaging was 19 days (range $-21-301$ days); $98 \%$ had imaging within 2 months of surgery. All cases had tumour clearly visible on MR or CT at the time of imaging with cross sectional area $>10 \mathrm{~cm}^{2}$ (median $30 \mathrm{~cm}^{2}\left(\right.$ range $\left.10-74 \mathrm{~cm}^{2}\right)$ ). ${ }^{201}$ Thallium $\left({ }^{201} \mathrm{Tl}\right)$ SPECT and ${ }^{18} \mathrm{~F}$-2-Fluoro-2-deoxy-D-glucose $\left({ }^{18} \mathrm{~F}\right.$-FDG) SPECT scans were obtained using a dual headed collimated gamma camera (DSTXL GESMVI, 1998). Images were acquired, reconstructed and reported using standard protocols as described previously (Walker et al, 2004). The spatial resolution of SPECT was $5 \mathrm{~mm} .{ }^{18} \mathrm{~F}$-FDG uptake was assessed as hypermetabolic or hypometabolic, if the intensity of signal within the known site of tumour was greater than or less than the equivalent site in the contralateral hemisphere, respectively. Similarly, scans were reported as having either increased or normal ${ }^{201} \mathrm{Tl}$ uptake at the site of the tumour compared with the contralateral hemisphere. Semiquantitative data was obtained as described previously (Walker et al, 2004). Reconstructed transverse slices in interfile format were imported into NIH Image (http://rsb.info.nih.gov/ nih-image). The tumour was located by comparison with MR or $\mathrm{CT}$ images and regions of interest (ROI) that delineated the part of tumour with the greatest difference in signal intensity and representative of the most aggressive biology were drawn. Uptake of ${ }^{201} \mathrm{Tl}$ or ${ }^{18} \mathrm{~F}-\mathrm{FDG}$ was measured in an axial slice containing the selected ROI and expressed as the ratio of the mean tumour counts in the ROI and the mean activity in an equivalent ROI mirrored in the contralateral hemisphere. ${ }^{18} \mathrm{~F}-\mathrm{FDG}$ and ${ }^{201} \mathrm{Tl}$ SPECT data reported as hypermetabolic or increased had uptake relative to the contralateral brain of $>0.9$ and $>1.1$, respectively. Postsurgery and pretherapy ${ }^{201} \mathrm{Tl}$ SPECT data was available for 46 patients and ${ }^{18}$ F-FDG SPECT for 48 patients.

\section{Chemotherapy}

Chemotherapy followed nuclear medicine imaging, with median time interval 19 days (range 2-152 days); 92\% had therapy within 2 months of imaging. PCV chemotherapy was administered according to standard clinical protocols (Levin et al, 1980). Lomustine (CCNU) $\left(110 \mathrm{mg} \mathrm{m}^{-2}\right)$, procarbazine $\left(60 \mathrm{mg} \mathrm{m}^{-2}\right)$ and vincristine $\left(1.4 \mathrm{mg} \mathrm{m}^{-2}\right.$ (maximum $2 \mathrm{mg}$ )) were given on Days 1 , $8-21$ and 8 and 29, respectively. Cycles were repeated every 6 weeks for a maximum of six cycles. The median pretherapy performance status, assessed using the ECOG scale, was 1 (range $0-4)$. Two high-grade cases died before completing the first cycle, the remainder received a median of four cycles with $33 \%$ completing six cycles. PCV was discontinued after cycle 1 in three cases, and treatment continued with temozolomide (2) or radiotherapy (1).

\section{Response assessment}

Response was assessed as described previously (Walker et al, 2006). A consultant neuroradiologist reviewed all available MR or CT images taken before, during and after chemotherapy, and at follow-up without knowledge of SPECT data, genotype or other clinical factors. The largest perpendicular diameters of the tumour were measured in axial sections of contrast-enhanced regions of T1-weighted MR or CT images or T2-weighted MR images. In 31 enhancing cases, response was assessed using Macdonald criteria (Macdonald et al, 1990). Response categories were: - CR-complete response (disappearance of all tumour, off steroids and neurologically stable or improved); PR - partial response $(50 \%$ or greater reduction in cross-sectional area, steroids stable or reduced, and neurologically stable or improved); PD - progressive disease $(25 \%$ or greater increase in cross sectional area or any new tumour on CT/MR images and/or neurologically worse with steroids stable or increased); SD - stable disease (all other situations). In 10 nonenhancing cases and three for whom contrast enhancement was not assessable, response was assessed using T2-weighted images (Hoang-Xuan et al, 2004; Stege et al, 2005). An additional minor response (MR) category $(>25-<50 \%$ reduction in cross-sectional area, steroids stable or reduced, and neurologically stable or improved) was included, as some cases showed radiological reduction in cross sectional T2W area of $>25-<50 \%$, accompanied by clinical benefit. None of the enhancing cases had radiological changes in this range. Response was not assessed due to early death (two cases) or insufficient imaging data (two cases).

\section{Clinical information}

Information regarding current management, follow-up and outcome was collected prospectively. Progression-free survival and OS were calculated from the start of PCV. The median follow-up time was 25 months (range 1-57) from start of chemotherapy and 40 months (range 16-57) for the 28 patients alive at study.

\section{Molecular genetics}

For each case regions of tumour histology in pretherapy resected tumours or biopsy specimens representative of the most aggressive tissue available and the overall pathology diagnosis were selected for study. Laser capture microdissection was used to enrich the tumour component in the samples for analysis and determination of allelic imbalance was carried out using paired normal and tumour samples and multiple simultaneous PCR amplification of a panel of microsatellite markers, followed by capillary electrophoresis and data analysis as described previously (Walker et al, 2003, 2004). The microsatellite panel included: chromosome 1- D1S2667, D1S508, D1S214 (1p36); chromosome 19- D19S412, D19S112, D19S596 (19q13). Additional markers, D1S468, D1S2795 (1p36) and D19S217, D19S572 (19q13) were used for cases that lacked informativity for given loci. 


\section{Statistics}

Statistical analysis was performed using SPSS. The Mann-Whitney test was used for non-normally distributed SPECT data and $\chi^{2}$ or Fisher's Exact tests were used for categorical data. Kaplan-Meier survival curves were obtained and differences in PFS or OS were tested for statistical significance using the log-rank test. Univariate and multivariate analysis was used to determine if genotype, ${ }^{201} \mathrm{Tl}$ and ${ }^{18}$ F-FDG uptake, gender, age, ECOG status, histopathology grade and subtype, contrast enhancement, therapy for primary or recurrent tumour had prognostic significance with respect to survival. Cox Regression multivariate analysis for factors significantly associated with survival in univariate analysis was by forward stepwise entry of parameters at a significance of 0.05 for entry and 0.01 for removal. $P$-values (two-tailed) $<0.05-$ 0.01 were considered weakly significant and those $<0.01$ of greater significance.

\section{RESULTS}

\section{SPECT data, histopathology and genotype}

Associations of SPECT data with histopathology and genotype have been reported previously in a larger series (Walker et al, 2004). In this subgroup of the original series, loss of $1 \mathrm{p} 36$ and $19 q 13$ was found in 8/15 OII, 6/15 OAII, 7/7 OIII, 3/11 OAIII and associations of SPECT data with genotype and histopathology grade are given in Table 1 . Increased ${ }^{201} \mathrm{Tl}$ uptake was seen in 6/15 OII, $1 / 13$ OAII, 5/7 OIII and 9/11 OAIII. ${ }^{18}$ F-FDG hypermetabolism was present in 4/15 OII, 2/15 OAII, 3/7 OIII, 6/11 OAIII. Using categorical or semiquantitative analyses, tumours with grade III pathology were more likely to show ${ }^{18}$ F-FDG hypermetabolism or increased ${ }^{201} \mathrm{Tl}$ uptake than grade II cases. Similarly, increased uptake of ${ }^{201} \mathrm{Tl}$ was more likely in cases with loss of $1 \mathrm{p} 36$ and $19 \mathrm{q} 13$ than in cases without these losses in the series, in grade II cases (Fisher-Exact- $1 \mathrm{p} / 19 \mathrm{q}$ loss $6 / 13,1 \mathrm{p} / 19 \mathrm{q}$ intact $1 / 15 P=0.029$, Mann - Whitney $P=\mathbf{0 . 0 0 1})$ and primary tumours $\left(\chi^{2}-1 \mathrm{p} / 19 \mathrm{q}\right.$ loss $10 / 18,1 \mathrm{p} / 19 \mathrm{q}$ intact $3 / 18 P=0.015$, Mann-Whitney $P=0.015$ ). There was no association between the $-1 \mathrm{p} /-19 \mathrm{q}$ genotype and ${ }^{18}$ F-FDG uptake. Five grade II cases with loss of $1 \mathrm{p} 36$ and $19 \mathrm{q} 13$ were hypermetabolic and had increased uptake of thallium, but no grade II cases with intact $1 \mathrm{p} 36$ and $19 \mathrm{q} 13$ had both features of elevated metabolism (Fisher Exact: $\mathrm{P}=0.013$ ). There was no difference in ${ }^{18} \mathrm{~F}$-FDG uptake in primary $v s$ recurrent tumours (Table 1). Increased ${ }^{201} \mathrm{Tl}$ uptake was more likely in the recurrent cases, however $50 \%$ of recurrent cases had grade III pathology compared with $34 \%$ of primary cases.

\section{Response}

Response, assessed in 44 cases given $>1$ cycle of chemotherapy (41 PCV, two PCV + temozolomide, one PCV + xrt), was signifi-

Table I Pretherapy SPECT data

\begin{tabular}{|c|c|c|c|c|c|c|c|c|c|c|}
\hline & \multicolumn{5}{|c|}{${ }^{18}$ F-FDG uptake } & \multicolumn{5}{|c|}{${ }^{201}$ TI uptake } \\
\hline $\begin{array}{l}\text { Grade II } \\
\text { Grade III }\end{array}$ & $\begin{array}{l}30 \\
18\end{array}$ & $\begin{array}{l}6 \\
9\end{array}$ & 0.030 & $\begin{array}{l}0.8(0.5-2.4) \\
\text { I.I }(0.7-2.4)\end{array}$ & 0.050 & $\begin{array}{l}28 \\
18\end{array}$ & $\begin{array}{r}7 \\
14\end{array}$ & 0.000 & $\begin{array}{l}1.0(0.8-7.6) \\
3.3(0.9-8.7)\end{array}$ & 0.002 \\
\hline $\begin{array}{l}\text { Cases with loss of }|p 36 / 19 q| 3 \\
\text { Cases without loss of }|p 36 /| 9 q \mid 3\end{array}$ & $\begin{array}{l}24 \\
24\end{array}$ & $\begin{array}{r}10 \\
5\end{array}$ & 0.12 & $\begin{array}{l}0.9(0.5-2.4) \\
0.8(0.5-2.0)\end{array}$ & 0.24 & $\begin{array}{l}23 \\
23\end{array}$ & $\begin{array}{r}14 \\
7\end{array}$ & 0.038 & $\begin{array}{l}2.1(0.9-7.6) \\
1.0(0.8-8.7)\end{array}$ & 0.047 \\
\hline
\end{tabular}

Pretherapy SPECT data in groups according to histology grade, genotype or therapy given to primary or recurrent tumour. Data given as $n-$ number of cases in each group, the number showing ${ }^{18} \mathrm{~F}-\mathrm{FDG}$ hypermetabolism or increased ${ }^{201} \mathrm{TI}$ uptake and the median and range for each group. $P$ - probability calculated using * $\chi^{2}$ test; $\sim$ Mann-Whitney test. Weakly significant $P$ values are given in italics; those of greater significance are given in bold.

Table 2 Response to chemotherapy

\begin{tabular}{|c|c|c|c|c|c|c|c|c|c|}
\hline & \multicolumn{9}{|c|}{ RESPONSE } \\
\hline & \multicolumn{3}{|c|}{ Loss of $1 \mathrm{p} 36$ and $19 q 13$} & \multicolumn{3}{|c|}{${ }^{18}$ F-FDG uptake } & \multicolumn{3}{|c|}{${ }^{201} \mathrm{Tl}$ uptake } \\
\hline & Yes & No & $P$ & Hypometabolic & Hypermetabolic & $\boldsymbol{P}$ & normal & increased & $\boldsymbol{P}$ \\
\hline All cases & $20 / 22(91 \%)$ & $7 / 22(32 \%)$ & 0.000 & $17 / 30(57 \%)$ & $10 / 14(71 \%)$ & 0.509 & 15/24 (63\%) & $12 / 18(67 \%)$ & 1.0 \\
\hline Primary tumours & $15 / 17(88 \%)$ & $7 / 17(41 \%)$ & 0.010 & 15/25 (60\%) & $7 / 9(78 \%)$ & 0.439 & |4/22 (64\%) & $8 / 10(80 \%)$ & 0.440 \\
\hline Recurrent tumours & $5 / 5(100 \%)$ & $0 / 5(0 \%)$ & 0.008 & $2 / 5(40 \%)$ & $3 / 5(60 \%)$ & 1.0 & I/2 (50\%) & $4 / 8(50 \%)$ & 1.0 \\
\hline Grade II & $13 / 14(93 \%)$ & $6 / 16(38 \%)$ & 0.002 & | 3/24 (54\%) & $6 / 6(100 \%)$ & 0.061 & $|3 / 2|(62 \%)$ & 6/7 (86\%) & 0.371 \\
\hline Grade III & $7 / 8(88 \%)$ & $1 / 6(17 \%)$ & 0.026 & $4 / 6(67 \%)$ & $4 / 8(50 \%)$ & 0.627 & $2 / 3(67 \%)$ & $6 / 11(55 \%)$ & 1.0 \\
\hline Ip36/ 19q13 loss & & & & I I/I2 (92\%) & $9 / 10(90 \%)$ & 1.0 & $8 / 8(100 \%)$ & $12 / 13$ (92\%) & 1.0 \\
\hline |p36/19q13 intact & & & & 6/18 (33\%) & I/4 (25\%) & 1.0 & $7 / 16(44 \%)$ & $0 / 5(0 \%)$ & 0.123 \\
\hline Enhancing tumours & $17 / 18(94 \%)$ & $4 / 13(31 \%)$ & 0.000 & $12 / 18(67 \%)$ & $9 / 13(69 \%)$ & 1.0 & $10 / 14(71 \%)$ & $11 / 17$ (65\%) & 1.0 \\
\hline Nonenhancing or enhancement not assessable & $3 / 4(75 \%)$ & $3 / 9(33 \%)$ & 0.266 & $5 / 12(42 \%)$ & I/I (100\%) & 0.462 & $5 / 10(50 \%)$ & I/I (100\%) & 1.0 \\
\hline
\end{tabular}

Response data is given for the series as well as in subgroups according to therapy given to primary or recurrent tumour, histopathology grade, genotype and response assessment based on enhancing tumour or T2-weighted MR. Data shows the proportion of responding cases in each group; data given as number of cases showing response that is $(C R+P R+M R) / n u m b e r$ of cases and (\%). $P$ - probability calculated using Fisher's exact test. Weakly significant $P$ values are given in italics; those of greater significance are given in bold 
cantly associated with combined loss of $1 \mathrm{p} 36$ and $19 \mathrm{q} 13$, but $7 / 22$ $(32 \%)$ with intact $1 \mathrm{p} 36$ and $19 \mathrm{q} 13$ also responded (Table 2). Response was seen in cases that were hypermetabolic and hypometabolic with respect to ${ }^{18}$ F-FDG uptake and in cases that showed normal or increased ${ }^{201} \mathrm{Tl}$ uptake. No associations between SPECT data and response were evident in the series (Table 2), or in subgroups of the series according to pathology subtype or grade, therapy given to primary or recurrent cases or $1 \mathrm{p} / 19 \mathrm{q}$ status. Similarly, when only the 31 enhancing tumours assessed using Macdonald criteria were considered, response was not associated with metabolism. In the 13 cases assessed using T2-weighted $\mathrm{MR}$, response was not significantly associated with genotype or metabolism. Analysis of semiquantitative data revealed no associations of metabolism with response in the series overall (Mann-Whitney test: ${ }^{18} \mathrm{~F}$-FDG $P=0.38 ;{ }^{201} \mathrm{Tl}$ uptake $P=0.98$ ), or in primary (Mann-Whitney test: ${ }^{18} \mathrm{~F}-\mathrm{FDG} P=1.0 ;{ }^{201} \mathrm{Tl}$ uptake $P=0.62$ ) or recurrent cases (Mann-Whitney test: ${ }^{18}$ F-FDG $P=1.0$; ${ }^{201} \mathrm{Tl}$ uptake $\left.P=0.60\right)$. When grouped according to $1 \mathrm{p} / 19 \mathrm{q}$ status there was no association between ${ }^{18} \mathrm{~F}$-FDG uptake and response (Figure 1). In cases with intact $1 \mathrm{p} / 19 \mathrm{q}$ all responders and $9 / 14$ nonresponders had ${ }^{201} \mathrm{Tl}$ uptake $\leqslant 1$ and five nonresponders (four recurrent tumours which showed $\mathrm{PD}$ and one primary tumour with SD) had increased ${ }^{201} \mathrm{Tl}$ uptake (Figure 1). This resulted in a statistically significant difference in ${ }^{201} \mathrm{Tl}$ uptake between responders and nonresponders in tumours with intact $1 \mathrm{p} / 19 \mathrm{q}$, which was not seen in categorical analysis (Table 2).

\section{Survival}

To compare the prognostic significance of metabolism with that of genotype, Kaplan-Meier plots for PFS and OS following PCV chemotherapy are given in Figure 2. Patients whose tumours showed ${ }^{18} \mathrm{~F}$-FDG hypermetabolism, increased ${ }^{201} \mathrm{Tl}$ uptake or intact 1 p36 and 19q13 had shorter PFS. Prolonged OS was significantly associated with loss of $1 \mathrm{p} 36$ and $19 \mathrm{q} 13$, while tumours with increased ${ }^{201} \mathrm{Tl}$ uptake showed a trend toward shorter OS. ${ }^{201} \mathrm{Tl}$ uptake and $1 \mathrm{p} / 19 \mathrm{q}$ genotype were independent prognostic factors for PFS and OS in multivariate analysis (Table 3 ). In primary cases, ${ }^{18} \mathrm{~F}$-FDG hypermetabolism was associated with shorter PFS (logrank: $P=0.0119$ ), and trends but not significant associations were seen between ${ }^{18} \mathrm{~F}$-FDG uptake and OS, and between ${ }^{201} \mathrm{Tl}$ uptake and PFS and OS. However, ${ }^{18}$ F-FDG hypermetabolism and increased ${ }^{201} \mathrm{Tl}$ uptake in primary cases were both significantly associated with shorter PFS and OS when adjusted for genotype (log-rank: PFS: ${ }^{18} \mathrm{~F}-\mathrm{FDG} P=\mathbf{0 . 0 0 0 5} ;{ }^{201} \mathrm{Tl} P=\mathbf{0 . 0 0 0 3}$; OS: ${ }^{18} \mathrm{~F}-\mathrm{FDG}$ $P=0.0227 ;{ }^{201} \mathrm{Tl} P=\mathbf{0 . 0 0 2 6}$ ) (Supplementary Data). Despite the small number of anaplastic cases, those with ${ }^{18}$ F-FDG hypermetabolism had decreased PFS (log-rank $P=0.023$ ). No significant associations between metabolism and survival were seen in recurrent cases, but numbers were low, especially for those with low metabolism.

${ }^{18} \mathrm{~F}$-FDG and ${ }^{201} \mathrm{Tl}$ uptake enabled significant prognostic discrimination for PFS in cases with or without the $-1 \mathrm{p} /-19 \mathrm{q}$ genotype, but for OS only in cases with intact $1 \mathrm{p} 36$ and $19 \mathrm{q} 13$ (Figure 3). Similar findings were observed if only primary cases were analysed (Supplementary Data). ${ }^{201} \mathrm{Tl}$ uptake was an independent prognostic factor for PFS and OS in multivariate analysis in cases with intact 1p/19q (Cox Regression: PFS-HR 7.0 (95\% CI 1.925.5), $P=$ 0.003; OS-HR 9.1 (95\% CI $2.2-37.9), P=\mathbf{0 . 0 0 2}$ ).

Of the 27 cases that responded to therapy, 10 had ${ }^{18}$ F-FDG hypermetabolism and 12 had increased ${ }^{201} \mathrm{Tl}$ uptake and elevated metabolism was significantly associated with short PFS (log-rank PFS: ${ }^{18}$ F-FDG $P=\mathbf{0 . 0 0 5} ;{ }^{201} \mathrm{Tl} P=0.0132$ ).

\section{DISCUSSION}

Although the association between ${ }^{201} \mathrm{Tl}$ and ${ }^{18} \mathrm{~F}$-FDG uptake and adverse prognosis has been reported previously in gliomas (Higa et al, 2001; Benard et al, 2003; Padma et al, 2003; Comte et al, 2006), this study represents the largest series of oligodendroglial neoplasms with response and outcome data following treatment by a uniform chemotherapeutic protocol, and is the only study to investigate metabolism and outcome in oligodendroglial neoplasms classified by molecular genetics. The cohort was drawn from a larger study of oligodendroglial neoplasms from a single treatment centre over a 3-year period (Walker et al, 2005, 2006) and reflects the range of patients with histopathological diagnosis of oligodendroglial tumour given PCV chemotherapy in the routine clinic. Associations of genotype with response and outcome in this subgroup compared well with the larger series that included $>90 \%$ of oligodendroglial neoplasms given PCV in the study period (Walker et al, 2006). Previously we have shown that elevated metabolism is associated with $1 \mathrm{p} / 19 \mathrm{q}$ loss, as well as with increased histopathological grade (Walker et al, 2004). Elevated metabolism was significantly more common in low-grade tumours with $1 \mathrm{p} / 19 \mathrm{q}$ loss than in those with intact 1p/19q (Walker et al, 2004). These findings remained valid for ${ }^{201} \mathrm{Tl}$ SPECT in the subset treated by PCV chemotherapy, but significant associations between genotype and ${ }^{18} \mathrm{~F}-\mathrm{FDG}$, which were weaker than ${ }^{201} \mathrm{Tl}$ in the previous report, were not observed in this subset, due to the lower numbers and reduced statistical power. As in the previous study, increased uptake of both ${ }^{18} \mathrm{~F}-\mathrm{FDG}$ and ${ }^{201} \mathrm{Tl}$ in low-grade cases was found only in those with $1 \mathrm{p} / 19 \mathrm{q}$ loss. The study included primary tumours given PCV as first oncology therapy as well as those receiving PCV following
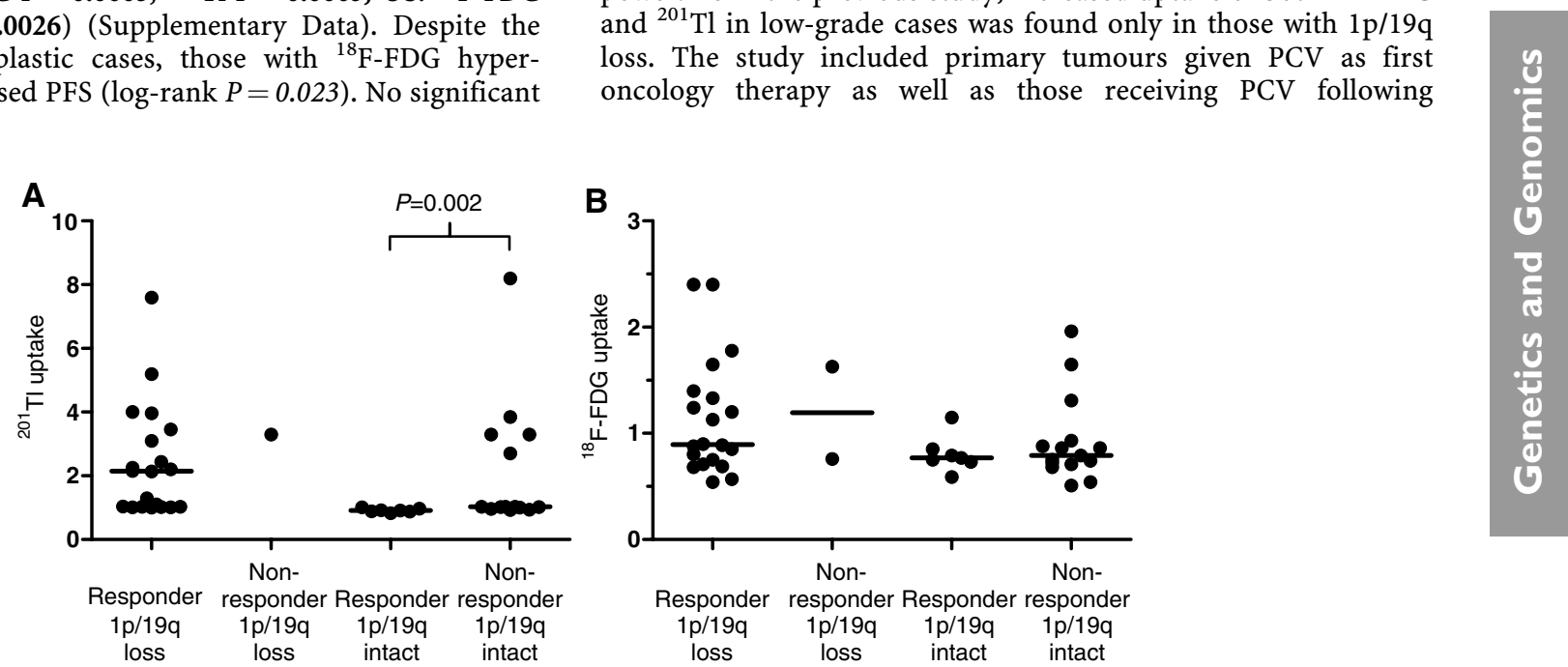

Figure I ${ }^{18} \mathrm{~F}-\mathrm{FDG}$ and ${ }^{20 I} \mathrm{TI}$ uptake expressed as a ratio relative to uptake in the contralateral brain in responders $(\mathrm{CR}+\mathrm{PR}+\mathrm{MR})$ and Nonresponders (SD + PD) to PCV chemotherapy with and without loss of I 36 and $19 q \mid 3$. (A) uptake of ${ }^{201} \mathrm{TI}$, (B) uptake of ${ }^{18}$ F-FDG. P-probability by Mann-Whitney test. Bars represent medians. 

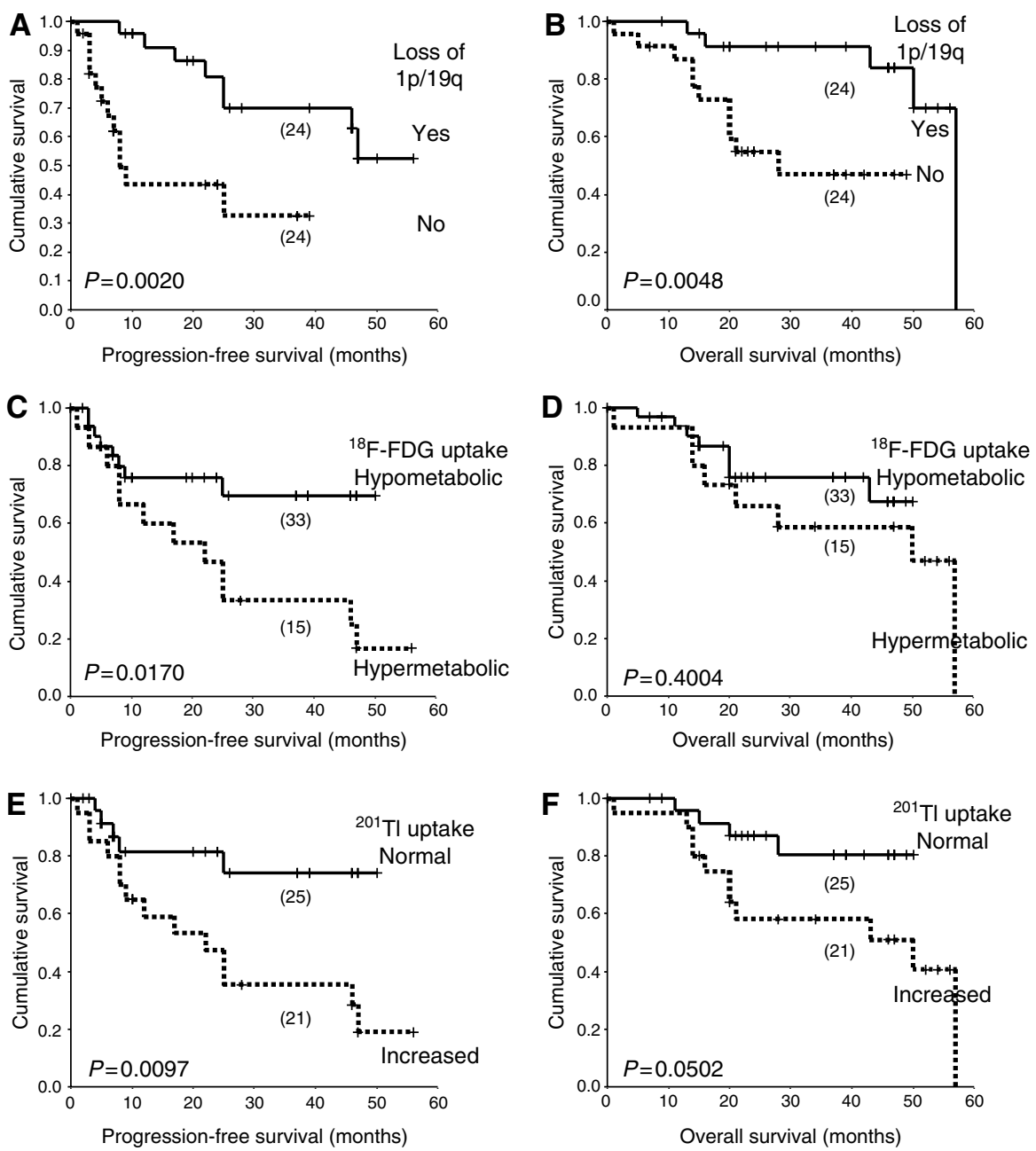

Figure 2 Outcome following PCV chemotherapy. Kaplan-Meier plots of (A, C and $\mathbf{E})$ PFS and (B, D and $\mathbf{F})$ OS according to: - (A and $\mathbf{B})$ I $/ \mathrm{l} / 9 \mathrm{q}$ status, $(\mathbf{C} \text { and } \mathbf{D})^{18} \mathrm{~F}$-FDG uptake, $(\mathbf{E}$ and $\mathbf{F}){ }^{201} \mathrm{Tl}$ uptake. Numbers in each group indicated in parentheses. P-Probabilities calculated by the log-rank test.

Table 3 Cox regression

\begin{tabular}{|c|c|c|c|c|c|c|}
\hline & \multicolumn{3}{|c|}{ PFS } & \multicolumn{3}{|c|}{ OS } \\
\hline & $\frac{\text { Univariate }}{P}$ & \multicolumn{2}{|c|}{ Multivariate } & $\frac{\text { Univariate }}{P}$ & \multicolumn{2}{|c|}{ Multivariate } \\
\hline $\begin{array}{l}\text { Loss of Ip36 and 19q I3 (yes* vs no) } \\
{ }^{18} \text { F-FDG uptake (hypo* vs hypermetabolic) }\end{array}$ & $\begin{array}{l}0.008 \\
0.008\end{array}$ & $\begin{array}{c}16.4\left(\begin{array}{c}(4.5-59.4) \\
R\end{array}\right. \\
R\end{array}$ & 0.000 & $\begin{array}{l}0.014 \\
0.286\end{array}$ & $\begin{array}{c}12.9(3.1-54.5) \\
\text { NS }\end{array}$ & 0.000 \\
\hline${ }^{20 I}$ TI uptake (normal* vs increased) & 0.008 & $14.9(4.1-53.4)$ & 0.000 & 0.045 & $9.5(2.6-35.1)$ & 0.000 \\
\hline Primary* vs recurrent & 0.001 & $\mathrm{R}$ & & 0.063 & NS & \\
\hline
\end{tabular}

Cox regression analysis for PFS and OS $(n=46)$ comparing SPECT data and genotype with significant clinicopathological factors. Histological subtype, presence or absence of contrast enhancement, age and ECOG status were not significantly associated with outcome in this cohort. Data given as the hazard ratio (HR) relative to baseline (*) and $95 \%$ confidence interval. NS - not significant in univariate analysis. P-Probability; R-term removed. Weakly significant $P$ values are given in italics; those of greater significance are given in bold.

recurrence after radiotherapy, reflecting clinical practice. The recurrent group had a higher proportion of cases with grade III pathology and was more likely to show increased ${ }^{201} \mathrm{Tl}$ uptake than primary cases. However, only 10 recurrent cases were investigated and as gliomas progress with time, they are likely to recur as a more aggressive tumour, which would be reflected in their metabolism. Further study in larger series would be necessary to explore metabolic differences between primary and recurrent tumours.

It has been suggested that increased metabolism may be related to therapeutic responsiveness to alkylating agents as these should exert a more beneficial effect in tumours with higher cell turnover and DNA-synthesis rates, which are known to correlate with higher glucose utilisation and metabolism (Herholz et al, 1993; Brock 
${ }^{18} \mathrm{~F}-\mathrm{FDG}$ uptake
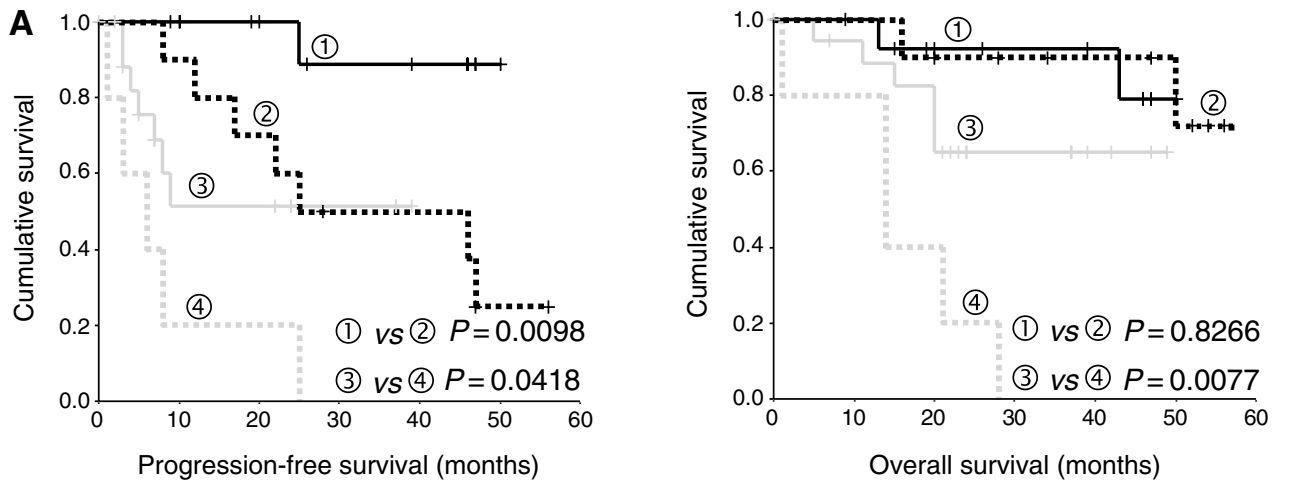
(1) $1 p / 19 q$ loss hypometabolic (14)
(2) $1 p / 19 q$ loss hypermetabolic (10)
(3) $1 p / 19 q$ intact hypometabolic (19)
(4) $1 p / 19 q$ Intact hypermetabolic (5)

${ }^{201}$ TI uptake
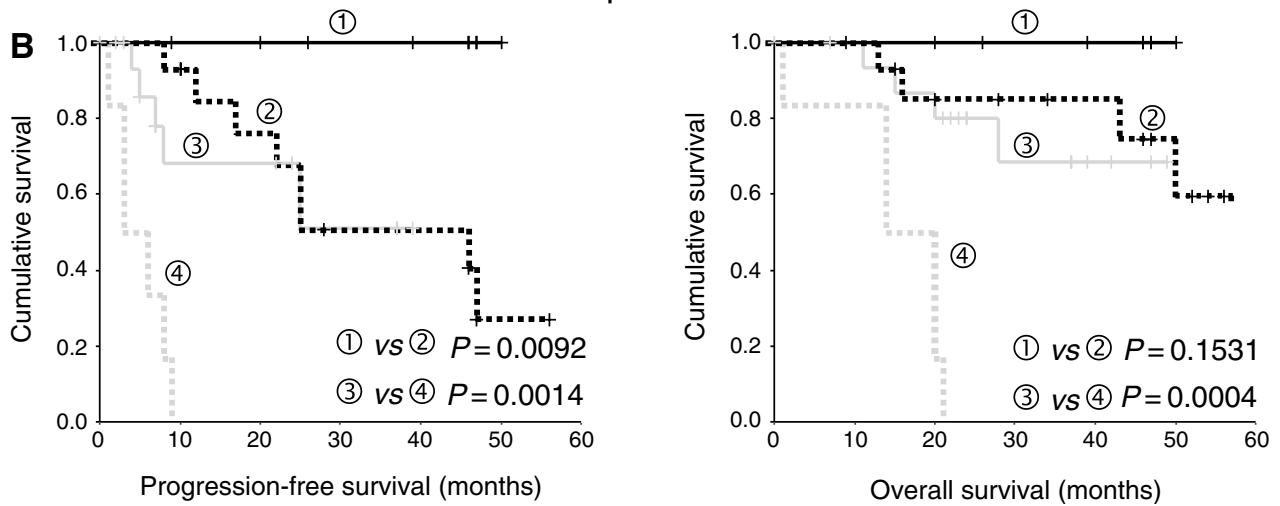

(1) $1 p / 19 q$ loss normal (9)

(2) $1 p / 19 q$ loss increased (14)

(3) $1 p / 19 q$ intact normal (16)

(4) $1 p / 19 q$ Intact increased (7)

Figure $3{ }^{18} \mathrm{~F}-\mathrm{FDG}$ and ${ }^{201} \mathrm{TI}$ uptake and survival in cases with or without the $-1 \mathrm{p} /-19 \mathrm{q}$ genotype. Kaplan-Meier plots of $(\mathbf{A}){ }^{18} \mathrm{~F}-\mathrm{FDG}$ uptake and $(\mathbf{B})$ ${ }^{20} \mathrm{TI}$ uptake comparing PFS and OS from start of PCV in cases grouped according to genotype and metabolism. Black lines - cases with I p/I9q loss, grey lines - cases with intact I / /9q. Solid lines normal ${ }^{201} \mathrm{TI}$ uptake or hypometabolic ${ }^{8} \mathrm{~F}-\mathrm{FDG}$ uptake, dashed lines increased ${ }^{201} \mathrm{TI}$ or hypermetabolic ${ }^{18} \mathrm{~F}-\mathrm{FDG}$ uptake. Numbers in each group indicated in parentheses. Probabilities calculated by the log-rank test.

et al, 2000; Prados, 2000). The methods for assessing response used in this study are widely utilised for gliomas, despite their limitations (Perry and Cairncross, 2003). As in other studies, response was strongly associated with the $-1 \mathrm{p} /-19 \mathrm{q}$ genotype (Cairncross et al, 1998; Ino et al, 2001; van den Bent, 2004). Tumours with or without features of elevated metabolism showed response following PCV chemotherapy. Elevated metabolism was not necessary for response and no associations with response were evident in the series as a whole or subdivisions according to grade, enhancement, or therapy given to primary or recurrent tumours. When subdivided by genotype, significant associations were only seen on analysis of semiquantitative data in cases with intact $1 \mathrm{p} /$ $19 \mathrm{q}$, where ${ }^{201} \mathrm{Tl}$ uptake was greater in nonresponders. However, $64 \%$ of these had normal ${ }^{201}$ Tl uptake and significant differences were not obtained in categorical analysis. Further study of a larger series would be necessary to resolve this discrepancy. In the series overall, response was strongly associated with the $-1 \mathrm{p} /-19 \mathrm{q}$ genotype, but not metabolism, suggesting that genetic lineage is dominant over metabolism in influencing chemosensitivity. Metabolism measured by ${ }^{201} \mathrm{Tl}$ or ${ }^{18} \mathrm{~F}$-FDG uptake is not a useful noninvasive diagnostic procedure to predict chemosensitivity in the absence of knowledge of genotype.

Although tumours with the $-1 \mathrm{p} /-19 \mathrm{q}$ genotype are likely to respond to chemotherapy, all oligodendroglial neoplasms inevitably recur, with wide variations in PFS even in those with the $-1 \mathrm{p} /-19 \mathrm{q}$ genotype (van den Bent, 2004). In addition, a significant proportion of oligodendroglial neoplasms with intact $1 \mathrm{p} / 19 \mathrm{q}$ may be chemosensitive, albeit associated with shorter PFS than those with 1p/19q loss (Ino et al, 2001; van den Bent et al,
2003; Walker et al, 2006). Identification of factors that enable prognostic stratification, would permit more effective clinical management and provision of chemotherapy to patients for which it may be of lasting benefit. In the present study, elevated ${ }^{201} \mathrm{Tl}$ and ${ }^{18}$ F-FDG uptake were both significantly associated with shorter PFS, in the series, in separate analysis of cases with or without the $-1 \mathrm{p} /-19 \mathrm{q}$ genotype and in cases that responded to therapy. ${ }^{201} \mathrm{Tl}$ uptake was an independent prognostic variable in multivariate survival analysis in the series and in cases with intact $1 \mathrm{p} / 19 \mathrm{q}$. These findings suggest that SPECT data may potentially be useful to predict cases for which chemotherapy may not be of long-term benefit and where additional therapy should be implemented early at the first signs of recurrence. However, the heterogeneity of the cohort is a limitation of the study. Primary and recurrent cases were included, although similar findings were obtained if primary cases only were considered. Oligodendrogliomas and oligoastrocytomas are both commonly treated by chemotherapy and their histopathological diagnosis is highly subjective and notoriously difficult. Classification by molecular genetics is now widely accepted (Reifenberger and Louis, 2003). As in our larger series, the proportion of oligodendrogliomas with loss of $1 \mathrm{p} / 19 \mathrm{q}(68 \%)$, was lower than reported in some studies, which may reflect diagnosis from small biopsies less prone to fixation artefact (Walker et al, 2005). Histopathological subtype was not associated with response or survival and elevated metabolism remained significantly associated with outcome after adjustment for histopathology subtype.

The most appropriate time to deliver therapy is a key question in the clinical management of patients that present with 
oligodendroglial neoplasms with low-grade pathology (van den Bent, 2004). Conventional indicators of progression to a highgrade glioma include contrast enhancement and histopathology. However, histopathological grading relies on subjective judgment of morphological features and is frequently associated with interobserver variability (Giannini et al, 2001), while contrast enhancement is also present in many low-grade oligodendroglial neoplasms (Walker et al, 2005; White et al, 2005). Elevated metabolism may also be considered an early indication of tumour progression (Higa et al, 2001; Benard et al, 2003; Padma et al, 2003; Vos et al, 2003; Datta et al, 2004), and in this study was seen in both low- and high-grade tumours. However, too few grade II cases with elevated metabolism or grade III cases with normal metabolism were available to permit assessment of the prognostic significance of SPECT data separately in low or high-grade cases.

In keeping with the known associations of the $-1 p /-19 q$ genotype with prolonged survival, cases with $1 \mathrm{p} / 19 \mathrm{q}$ loss and elevated metabolism had longer PFS and OS than cases with intact $1 p / 19 q$ and high metabolism. Intriguingly, these data suggest that there may be differences in the thresholds at which metabolism becomes associated with aggressive behaviour and/or differences in the baseline biology of oligodendrogliomas with or without the $-1 \mathrm{p} /-19 \mathrm{q}$ genotype. However, further studies with more biological markers would be required to address this issue. Despite the limitations of the study and its small heterogeneous cohort, our findings show promise that metabolism may have prognostic significance irrespective of genotype. Confirmation in a larger more homogeneous series, particularly primary tumours, is therefore essential.

From a molecular genetic viewpoint, progression in gliomas is associated with sequential accumulation of genetic alterations with consequent deregulation of the cell cycle and increased angiogenesis (Hartmann et al, 2004; Jeuken et al, 2004). Upregulation of angiogenesis factors and a variety of genetic alterations including deletion of CDKN2A, loss of chromosome 10, downregulation of
ATase and cyclooxygenase-2 expression have been associated with progression and poor prognosis in oligodendroglial neoplasms (Jaeckle et al, 1998; Castilla et al, 2003; Hartmann et al, 2004; Jeuken et al, 2004). While genetic analysis to determine the $1 \mathrm{p} / 19 \mathrm{q}$ status may be introduced into routine diagnostic practice, no single test is presently available to indicate tumour progression and poor outcome. Features of elevated metabolism in this and other studies of oligodendrogliomas (Giammarile et al, 2004) or gliomas (Vos et al, 2003; Pardo et al, 2004) have been associated with poor prognosis and may result as a consequence of deregulation of signal transduction through a variety of genetic changes, rather than being associated with a single genetic event. These data suggest that, in addition to the $1 \mathrm{p} / 19 \mathrm{q}$ status, metabolic scans may be potentially useful to predict prognosis and identify cases with short-term benefit from PCV. This may be of greatest utility in determining those cases with intact $1 \mathrm{p} / 19 \mathrm{q}$ that will benefit from chemotherapy.

In this initial study, we have shown that elevated metabolism is not predictive of response to therapy, but may be associated with poor survival following therapy irrespective of genotype. Further confirmation in a larger series is therefore warranted.

\section{ACKNOWLEDGEMENTS}

This research was made possible through the support of Clatterbridge Cancer Research Trust, Clatterbridge Centre for Oncology, the Walton Centre for Neurology and Neurosurgery and the Dept of Nuclear Medicine, Royal University Hospital, Liverpool. We thank Dr DR Sibson, Clatterbridge Cancer Research Trust, for helpful support and discussion.

Supplementary Information accompanies the paper on British Journal of Cancer website (http://www.nature.com/bjc)

\section{REFERENCES}

Benard F, Romsa J, Hustinx R (2003) Imaging gliomas with positron emission tomography and single-photon emission computed tomography. Semin Nucl Med 33: $148-162$

Brock CS, Young H, O'Reilly SM, Matthews J, Osman S, Evans H, Newlands ES, Price PM (2000) Early evaluation of tumour metabolic response using (18F)fluorodeoxyglucose and positron emission tomography: a pilot study following the phase II chemotherapy schedule for temozolomide in recurrent high-grade gliomas. Br J Cancer 82: 608-615

Cairncross JG, Ueki K, Zlatescu MC, Lisle DK, Finkelstein DM, Hammond RR, Silver JS, Stark PC, Macdonald DR, Ino Y, Ramsay DA, Louis DN (1998) Specific genetic predictors of chemotherapeutic response and survival in patients with anaplastic oligodendrogliomas. J Natl Cancer Inst 90: $1473-1479$

Castilla EA, Prayson RA, Kanner AA, Rybicki LA, Tubbs RR, Vogelbaum MA, Barnett GH (2003) Cyclooxygenase-2 in oligodendroglial neoplasms. Cancer 98: $1465-1472$

Comte F, Bauchet L, Rigau V, Hauet JR, Fabbro M, Coubes P, Chevalier J, Mariano-Goulart D, Rossi M, Zanca M (2006) Correlation of preoperative thallium SPECT with histological grading and overall survival in adult gliomas. Nucl Med Commun 27: 137-142

Datta NR, Pasricha R, Gambhir S, Prasad SN, Phadke RV (2004) Comparative evaluation of 201Tl SPECT and CT in the follow-up of irradiated brain tumors. Int J Clin Oncol 9: 51-58

Engelhard HH, Stelea A, Mundt A (2003) Oligodendroglioma and anaplastic oligodendroglioma: clinical features, treatment, and prognosis. Surg Neurol 60: 443-456

Giammarile F, Cinotti LE, Jouvet A, Ramackers JM, Saint Pierre G, Thiesse P, Jouanneau E, Guyotat J, Pelissou-Guyotat I, Setiey A, Honnorat J, Le Bars D, Frappaz D (2004) High and low grade oligodendrogliomas (ODG): correlation of amino-acid and glucose uptakes using PET and histological classifications. J Neurooncol 68: 263-274

Giannini C, Scheithauer BW, Weaver AL, Burger PC, Kros JM, Mork S, Graeber MB, Bauserman S, Buckner JC, Burton J, Riepe R, Tazelaar HD, Nascimento AG, Crotty T, Keeney GL, Pernicone P, Altermatt H (2001) Oligodendrogliomas: reproducibility and prognostic value of histologic diagnosis and grading. J Neuropathol Exp Neurol 60: 248-262

Hartmann C, Mueller W, von Deimling A (2004) Pathology and molecular genetics of oligodendroglial tumors. J Mol Med 82: 638-655

Herholz K, Pietrzyk U, Voges J, Schroder R, Halber M, Treuer H, Sturm V, Heiss WD (1993) Correlation of glucose consumption and tumor cell density in astrocytomas. A stereotactic PET study. J Neurosurg 79: $853-858$

Higa T, Maetani S, Yoichiro K, Nabeshima S (2001) TI-201 SPECT compared with histopathologic grade in the prognostic assessment of cerebral gliomas. Clin Nucl Med 26: 119-124

Hoang-Xuan K, Capelle L, Kujas M, Taillibert S, Duffau H, Lejeune J, Polivka M, Criniere E, Marie Y, Mokhtari K, Carpentier AF, Laigle F, Simon JM, Cornu P, Broet P, Sanson M, Delattre JY (2004) Temozolomide as initial treatment for adults with low-grade oligodendrogliomas or oligoastrocytomas and correlation with chromosome $1 \mathrm{p}$ deletions. J Clin Oncol 22: 3133-3138

Ino Y, Betensky RA, Zlatescu MC, Sasaki H, Macdonald DR, StemmerRachamimov AO, Ramsay DA, Cairncross JG, Louis DN (2001) Molecular subtypes of anaplastic oligodendroglioma: implications for patient management at diagnosis. Clin Cancer Res 7: 839-845

Jaeckle KA, Eyre HJ, Townsend JJ, Schulman S, Knudson HM, Belanich M, Yarosh DB, Bearman SI, Giroux DJ, Schold SC (1998) Correlation of tumor $\mathrm{O} 6$ methylguanine-DNA methyltransferase levels with survival of malignant astrocytoma patients treated with bis-chloroethylnitrosourea: a Southwest Oncology Group study. J Clin Oncol 16: 3310-3315

Jager HR, Waldman AD, Benton C, Fox N, Rees J (2005) Differential Chemosensitivity of Tumor Components in a Malignant Oligodendroglioma: 
Assessment with Diffusion-Weighted, Perfusion-Weighted, and Serial Volumetric MR Imaging. AJNR Am J Neuroradiol 26: 274-278

Jenkinson MD, Smith TS, Joyce K, Fildes D, du Plessis DG, Warnke PC, Walker C (2005) MRS of oligodendroglial tumors: correlation with histopathology and genetic subtypes. Neurology 64: 2085-2089

Jeuken JW, von Deimling A, Wesseling P (2004) Molecular pathogenesis of oligodendroglial tumors. J Neurooncol 70: $161-181$

Kleihues P, Cavanee W (2000) Pathology and genetics of tumors of the nervous system. In: Kleihues P, Cavanee WK (eds). Lyon: IARC Press

Levin VA, Edwards MS, Wright DC, Seager ML, Schimberg TP, Townsend JJ, Wilson CB (1980) Modified procarbazine, CCNU, and vincristine (PCV 3) combination chemotherapy in the treatment of malignant brain tumors. Cancer Treat Rep 64: 237-244

Levivier M, Wikler Jr D, Massager N, David P, Devriendt D, Lorenzoni J, Pirotte B, Desmedt F, Simon Jr S, Goldman S, Van Houtte P, Brotchi J (2002) The integration of metabolic imaging in stereotactic procedures including radiosurgery: a review. J Neurosurg 97: 542-550

Macdonald DR, Cascino TL, Schold Jr SC, Cairncross JG (1990) Response criteria for phase II studies of supratentorial malignant glioma. J Clin Oncol 8: $1277-1280$

Padma MV, Said S, Jacobs M, Hwang DR, Dunigan K, Satter M, Christian B, Ruppert J, Bernstein T, Kraus G, Mantil JC (2003) Prediction of pathology and survival by FDG PET in gliomas. J Neurooncol 64: $227-237$

Pardo FS, Aronen HJ, Fitzek M, Kennedy DN, Efird J, Rosen BR, Fischman AJ (2004) Correlation of FDG-PET interpretation with survival in a cohort of glioma patients. Anticancer Res 24: 2359-2365

Perry JR, Cairncross JG (2003) Glioma Therapies: How to Tell Which Work? J Clin Oncol 21: $3547-5349$

Prados MD (2000) Systemic Chemotherapy. In: Bernstein M, Berger M (eds) Neuro-Oncology. Thieme: Verlag, pp 226-233

Reifenberger G, Louis DN (2003) Oligodendroglioma: toward molecular definitions in diagnostic neuro-oncology. J Neuropathol Exp Neurol 62: $111-126$

Smith JS, Perry A, Borell TJ, Lee HK, O’Fallon J, Hosek SM, Kimmel D, Yates A, Burger PC, Scheithauer BW, Jenkins RB (2000) Alterations of chromosome arms $1 \mathrm{p}$ and $19 \mathrm{q}$ as predictors of survival in oligodendrogliomas, astrocytomas, and mixed oligoastrocytomas. J Clin Oncol 18: $636-645$

Stege EM, Kros JM, de Bruin HG, Enting RH, van Heuvel I, Looijenga LH, van der Rijt CD, Smitt PA, van den Bent MJ (2005) Successful treatment of low-grade oligodendroglial tumors with a chemotherapy regimen of procarbazine, lomustine, and vincristine. Cancer 103: 802-809

Stokkel M, Stevens H, Taphoorn M, Van Rijk P (1999) Differentiation between recurrent brain tumour and post-radiation necrosis: the value of 201Tl SPET versus 18F-FDG PET using a dual-headed coincidence camera-a pilot study. Nucl Med Commun 20: 411-417

van den Bent MJ (2004) Diagnosis and management of oligodendroglioma. Semin Oncol 31: 645-652

van den Bent MJ, Looijenga LH, Langenberg K, Dinjens W, Graveland W, Uytdewilligen L, Sillevis Smitt PA, Jenkins RB, Kros JM (2003) Chromosomal anomalies in oligodendroglial tumors are correlated with clinical features. Cancer 97: 1276 - 1284

Vos MJ, Hoekstra OS, Barkhof F, Berkhof J, Heimans JJ, Van Groeningen CJ, Vandertop WP, Slotman BJ, Postma TJ (2003) Thallium-201 singlephoton emission computed tomography as an early predictor of outcome in recurrent glioma. J Clin Oncol 21: 3559-3565

Walker C, du Plessis DG, Fildes D, Haylock B, Husband D, Jenkinson MD, Joyce KA, Broome J, Kopitski K, Prosser J, Smith T, Vinjamuri S, Warnke PC (2004) Correlation of molecular genetics with molecular and morphological imaging in gliomas with an oligodendroglial component. Clin Cancer Res 10: 7182 - 7191

Walker C, du Plessis DG, Joyce KA, Fildes D, Gee A, Haylock B, Husband D, Smith T, Broome J, Warnke PC (2005) Molecular pathology and clinical characteristics of oligodendroglial neoplasms. Ann Neurol 57: 855-865

Walker C, du Plessis DG, Joyce KA, Machell Y, Thomson-Hehir J, Al Haddad SA, Broome JC, Warnke PC (2003) Phenotype versus genotype in gliomas displaying inter- or intratumoral histological heterogeneity. Clin Cancer Res 9: $4841-4851$

Walker C, Haylock B, Husband D, Joyce KA, Fildes D, Jenkinson MD, Smith T, Broome J, du Plessis DG, Warnke PC (2006) Clinical use of genotype to predict chemosensitivity in oligodendroglial tumors. Neurology 66: $1661-1667$

Warnke PC (1998) Physiological characterization of malignant oligodendrogliomas responding to PCV chemotherapy. J Neurosurg 88: 399A

Warnke PC, Kopitzki K, Ostertag CB, Vinjamuri S (2003) The role of functional imaging in brain tumours. World J Nucl Med 2: $37-44$

Warnke PC, Timmer J, Ostertag CB, Kopitzki K (2005) Capillary physiology and drug delivery in central nervous system lymphomas. Ann Neurol 57: $136-139$

White ML, Zhang Y, Kirby P, Ryken TC (2005) Can tumor contrast enhancement be used as a criterion for differentiating tumor grades of oligodendrogliomas? AJNR Am J Neuroradiol 26: $784-790$ 